\title{
Impact of Cadmium on the Endocrine and Exocrine Sexual Activity in the Adult Male and Female Wistar Rats: Determination of an Apoptotic Process
}

\author{
Manel Boujelben ${ }^{1}$, Raed Abdennabi ${ }^{2,3^{*}}$, Fadhel Guermazi ${ }^{4}$ and Abdelfattah Elfeki ${ }^{1}$ \\ ${ }^{1}$ Laboratory of Animal Ecophysiology, Faculty of Sciences, Sfax, Tunisia \\ ${ }^{2}$ Laboratory of Plant Biotechnology, Faculty of Sciences, University of Sfax, BP 1171, 3000, Tunisia \\ ${ }^{3}$ Laboratory of Pharmacognosy and Natural Products Chemistry, Athens 15771, Greece \\ ${ }^{4}$ Laboratory of Nuclear Medicine, CHU Habib-Bourguiba of Sfax, Tunisia
}

\begin{abstract}
This study deals with the impact of chronic exposure to cadmium on male and female's fertility in rats. In fact, some male and female rats are given distilled water for drinking ( $\mathrm{T}$ : controls), whereas the other ones are given distilled water enriched with chloride cadmium, either 10 (C1 group) or $20 \mathrm{mg} / \mathrm{l}$ (C2 group) for $1,5,10,15,30,45,60$ or 90 days. In male rats, Cadmium, which induced a pathological change in spermatogenesis, is observed by histological studies: arrest of cell germ maturation, Then, an alteration of the structure of the seminiferous tubes with blockage of spermatogenesis (presence of male gametes without flagella or total absence of spermatozoa and destruction of the sertoli cells, testified by the presence of spans). Then, a decrease of the motility and the number of spermatozoa at the end of the treatment indicates the local cytotoxic effect of cadmium (Cd) on spermatogenesis, inducing an apoptotic phenomenon revealed by borated toluidine blue in the testicular cells, which affects the different stages of spermatogenesis. Serum testosterone level is found to be low at the beginning of the treatment, reaches a peak, then returns to the control values and even exceeds them in spite of the continuation of the treatment. It is therefore a hormonal adaptation to this pollutant. In female rats, the practiced vaginal smears revealed the oestrus phase in all the groups. Exposed females are mated to control males, and fertility is assessed later by counting the number of pregnancies. Fertility is found to be reduced in females of $\mathrm{C} 1$ and $\mathrm{C} 2$ groups as compared to control females (T group).
\end{abstract}

Keywords: Cadmium; Rat; Fertility; Apoptosis

\section{Introduction}

Nowadays, due to a complex anthropic activity and the multiplicity of industrial installations, the degree of atmospheric pollution by several pollutants, such as heavy metals, has been changing in recent years. The concentration of $\mathrm{Cd}$ in the air becomes very high, which threatens all living beings (plants, animals and humans, especially children). It has been shown that $\mathrm{Cd}$ can cross the placental barrier since it is found in fetuses after intoxication of their mothers. For example, research on environmental toxicology has reported the cytotoxic and oxidative effects of these pollutants. Indeed, heavy metals have toxic properties affecting the development of the body from the fetal stage. The effect of environmental contaminants on pregnancy, particularly on the development of the fetus, is one of the "hot" topics of public health. The use of biomarkers is essential to detect, prevent and treat the early and reversible effects of these pollutants. During this study, we investigated cadmium as a pollutant and prooxidant trace element, and its cytotoxic effects, through some biomarkers which are classified into three types: biomarkers of exposure, of effect, and of susceptibility. In this paper, we will focus on the effect type of biomarkers, because the latter, that is to say the biomarker of susceptibility, which depends on the subject matter, is constant in our study since we work on a constant and homogeneous animal support such as the "wistar" white rat. Regarding the exposure to biomarkers. The objective of this study is to explore the impact of chronic exposures to cadmium on the reproductive functions in adult male and female rats. As biomarkers of effect, we chose sexual function, through epididymal sperm analysis (sperm concentration and motility rate), the rate of serum testosterone, testicular histology for males and vaginal smears for oestral stage detection, pregnancy rate, average number of implantations for female rats.

\section{Materials and Methods}

\section{Ethics statement}

The Ethics Committee of the Faculty of Sciences of Sfax approved of the experimental protocol used in the present study. The guidelines established by this Faculty to take care and use of laboratory animals were followed in all the experimental procedures.

\section{Animals}

Male and female Wistar rats weighing between 150 and $180 \mathrm{~g}$ were obtained from the animal house of Sfax University, Tunisia. Animals were controlled under the following conditions: temperature $\left(25 \pm 2^{\circ} \mathrm{C}\right)$, humidity $(60 \pm 10 \%)$, a $12 / 12 \mathrm{~h}$ light-dark cycle and allowed water and food. They were fed on concentrated tablets (SICO, Sfax). The drinking water was controlled. Some rats received distilled water $(\mathrm{T})$, the other ones received water rich in chloride cadmium, at two concentrations: $10 \mathrm{mg} / 1$ (C1 group) or $20 \mathrm{mg} / \mathrm{l}$ (C2 group). This treatment lasted $1,5,10,15,30,45,60$, or 90 days, depending on the groups.

\section{Chemicals}

Cadmium, and solvents were purchased from Sigma-Aldrich.

*Corresponding author: Raed Abdennabi, Laboratory of Pharmacognosy and Natural Products Chemistry, Athens 15771, Greece, Tel: +21698694398; E-mail raedabdennabi@gmail.com

Received February 16, 2018; Accepted February 25, 2018; Published February 28, 2018

Citation: Boujelben M, Abdennabi R, Guermazi F, Elfeki A (2018) Impact of Cadmium on the Endocrine and Exocrine Sexual Activity in the Adult Male and Female Wistar Rats: Determination of an Apoptotic Process. J Environ Anal Toxicol 8: 552. doi: 10.4172/2161-0525.1000552

Copyright: @ 2018 Boujelben M, et al. This is an open-access article distributed under the terms of the Creative Commons Attribution License, which permits unrestricted use, distribution, and reproduction in any medium, provided the original author and source are credited. 
Citation: Boujelben M, Abdennabi R, Guermazi F, Elfeki A (2018) Impact of Cadmium on the Endocrine and Exocrine Sexual Activity in the Adult Male and Female Wistar Rats: Determination of an Apoptotic Process. J Environ Anal Toxicol 8: 552. doi: 10.4172/2161-0525.1000552

Page 2 of 7

\section{Determination of the sexual stage in female rats}

This was conducted by vaginal smears on the day of sacrifice. Thus, a cotton swab is dipped in physiological fluid $(\mathrm{NaCl} 9 \%)$ is introduced into the vagina of the female rat. The smear is spread on a slide and then observed under an optical microscope.

The vaginal cycle of the female rat lasts between 4 and 5 days with the following stages observed under the microscope.

- Dioestrus: this is the phase of sexual rest characterized by the presence of leucocytes and epithelial cells.

- Prooestrus: It is characterized by the presence of epithelial cells with or without keratinized cells.

- Oestrus: It is characterized by dead cells with geometrical contour deprived of nuclei, isolated or plated to one another, these cells are called keratinized or horny cells.

- Postestrus or metoestrus: It is characterized by the presence of keratinized cells and leucocytes.

Pregnancy rate: After 90 days of treatment, some animals are not sacrificed. They were used to carry out inter-group crossings as follows:

- Control females mated with control males.

- Control females mated with $\mathrm{C} 1$ treated males.

- Control females mated with C2 treated males.

- $\mathrm{C} 1$ females mated with control males.

- Female C2 mated with control males.

For this purpose, the male and female rats are put together for 10 days after which the males are removed, then, the females are sacrificed with ether and their are open. The pregnancy rate as well as the litter size, when pregnancy is positive, are determined.

\section{Analysis of epididymal spermatozoa}

For the preparation of these spermatozoa, the males are anesthetized with ether, an abdominal incision is made and the tail of the epididymis and the initial part of the different canal are removed and placed rapidly in $2 \mathrm{ml}$ of Earles's buffer. at $35^{\circ} \mathrm{C}$. They are dilacerated in this buffer with tweezers. After 10 to 15 minutes, spermatozoa spontaneous dispersion is achieved. The counting of their number and the measurement of their motility rate are carried out using a Mallassez cell under an optical microscope.

\section{Assay of serum testosterone}

This assay was carried out by radioimmunoassay using KIT Immunotech (réf. 1119).

\section{Histological analyses}

Classical procedures are used for histology. After fixation in Bouin solution, pieces of fixed tissue are embedded into paraffin, cut into $5 \mu \mathrm{m}$ slices and colored with hematoxyline-eosine.

\section{Statistical analysis}

Two independent experiments are performed. Data are expressed as mean \pm standard deviation (SD). Statistical significance are assessed by ANNOVA test. ${ }^{*} \mathrm{P}<0.05$ are considered statistically significant.

\section{Results}

\section{Male reproductive function}

Effect of cadmium on the number and motility of male sex cells: Administration of cadmium chloride in drinking water for 90 days induced a decrease of the number and motility of sperm in male rats, depending on the administered dose (Figure 1).

Testicular histology: Testicular histology of the control rats (Figure 2) shows too tight seminiferous tubes with too small interstitial spaces. On the wall of these tubes, one can easily observe the different stages of spermatogenesis that are conducted in a centripetal manne (Figure 3). It can be observed that small-sized spermatogonia, are located close to the basement membrane, then larger spermatocytes I and II with large nuclei in the division phase, spermatids of small size, and spermatozoa with flagella filling almost all the light of these tubes. However, in the cadmium-treated rats, these different stages are strongly affected and there are tubes completely devoid of mature gametes (absence of flagella or total absence of spermatozoa) (Figures $3 \mathrm{~B}$ and $3 \mathrm{C}$ ). In addition, they are atrophied with abundant interstitial spaces (Figure $2 \mathrm{~B}$ ) and with appearance of empty trabeculae between the germinal cells at their wall (destruction of sertoli cells) (Figure 3D). This histological failure is more important from the 5th to the 10th day for $\mathrm{C} 1$ and the 5th day only for C2. Beyond these periods, there is a partial improvement of testicular histology despite the cadmium treatment. The percentages of seminiferous tubules lacking mature spermatozoa drop only to $70 \%$, $55 \%$ and $63 \%$, respectively, on the 45th, 60th and 90th days for $\mathrm{C} 1$ and to $89 \%, 62 \%$ and $66 \%$, respectively, on the 10 th, 60 th and 90 th days for C2.

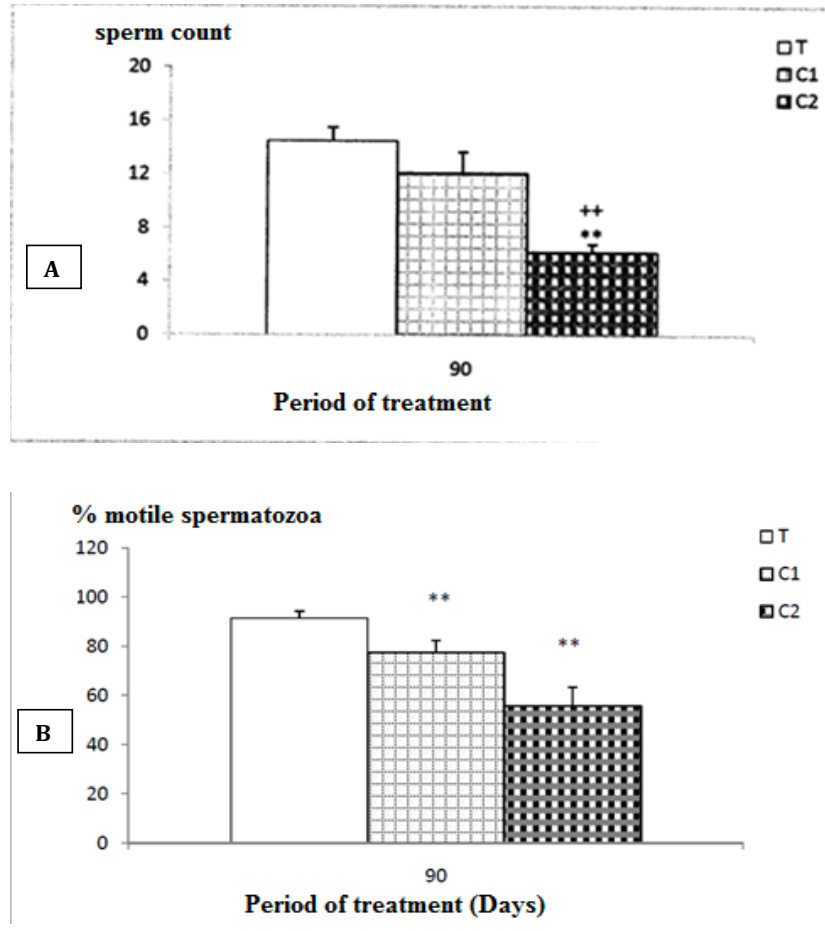

Figure 1: Evolution of number (A) and motility (B) (\%) of epididymitis spermatozoa in control rats $(T)$ and rats treated with cadmium chloride $(\mathrm{C} 1$ and $\mathrm{C} 2)$ for 90 days. The values represent the mean \pm Standard Deviation $(n=38)$. ${ }^{* *}: \mathrm{P} \leq 0.01$ compared to the control rats. $++: \mathrm{P} \leq 0.01$ compared with the treated rats $\mathrm{C} 1$. 
Citation: Boujelben M, Abdennabi R, Guermazi F, Elfeki A (2018) Impact of Cadmium on the Endocrine and Exocrine Sexual Activity in the Adult Male and Female Wistar Rats: Determination of an Apoptotic Process. J Environ Anal Toxicol 8: 552. doi: 10.4172/2161-0525.1000552

Page 3 of 7
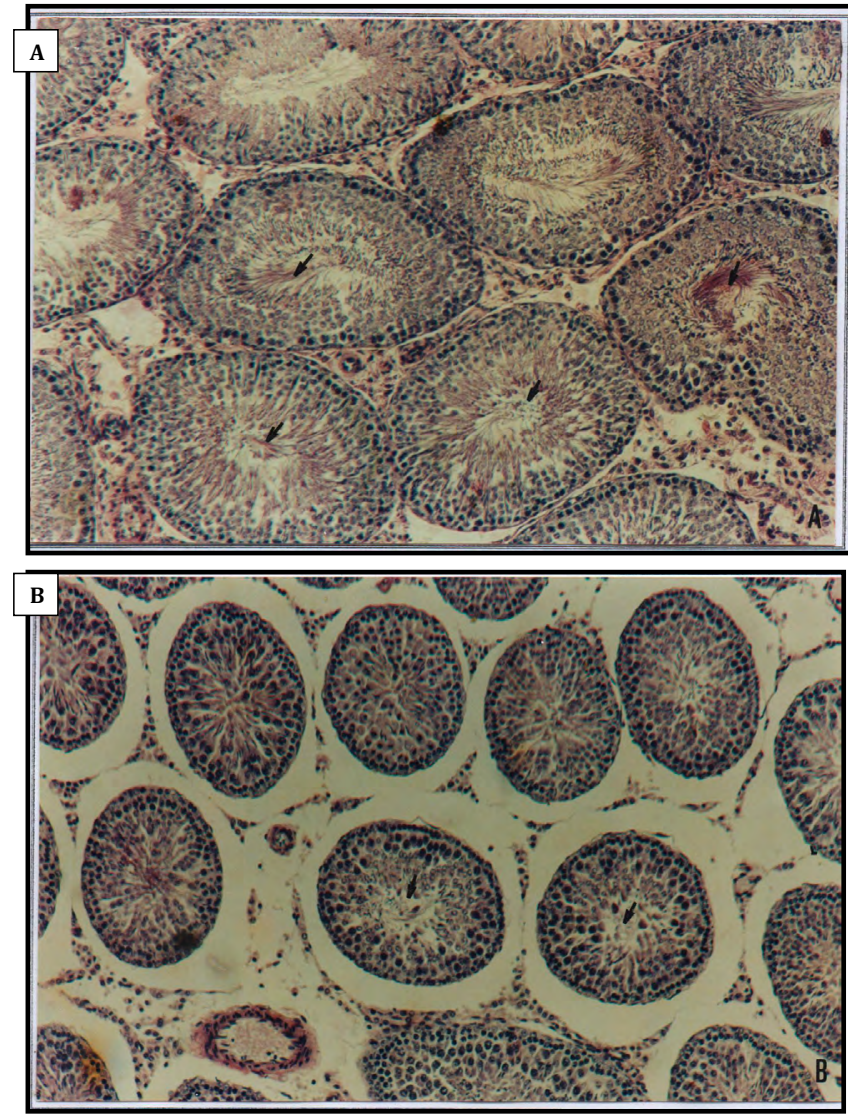

Figure 2: Histological structures of the control rat testes $(\mathbf{A})$ and treated with cadmium chloride $(B)$ administered in drinking water at a concentration of 10 $\mathrm{mg} / \mathrm{l}$ for 60 days. Coloring: hematoxylin-eosin (Grx100).

This partial improvement of testicular histology seems to be a consequence of the correction of the serum testosterone level reported under the same conditions, and explained by the intervention of the gonado-pituitary feedback phenomenon. However, testicular failure persists despite this partial improvement. This reflects the local testicular cytological effect of cadmium=which persists until the end of the treatment despite the correction of the endocrine sexual function; according to the results of the epididymal sperm count and the intergroup grouping.

Demonstration of the apoptosis phenomenon: The presence of apoptotic cells revealed borated toluidine blue in the testis. Our results showed that from the 60th day onward, some testicular sections show apoptotic cells of dense nuclei in the wall and towards the lumen of the seminiferous tubules (Figures $4 \mathrm{~B}$ and $4 \mathrm{C}$ ). Indeed, the condensation of chromatin is one of the first signs of programmed cell death or apoptosis. The cytotoxic effect of cadmium thus seems to be exerted by a phenomenon of apoptosis which affects the different stages of spermatogenesis.

Serum testosterone level: The radioimmunoassay of the male sex hormone shows that the secretion of testosterone is "age-dependent" where a peak is recorded on the 10th day, then, the testosterone levels stabilize near this maximum value. This "dependent age" evolution of control rats is not different from that of the cadmium treatment.
However, at the beginning of the treatment, the treated rats have a statistically significant variation in the level of this hormone relative to the controls. Indeed, this rate shows a significant decrease on day 1 and day 5 of cadmium treatment in Group $\mathrm{C} 1$ rats. Beyond 5 days, this rate is corrected despite the continuation of the treatment to find that of the controls or even exceed it for example on the 30th day for $\mathrm{C} 1$ and on the 5th day for C2 (Figure 5). This rapid correction of serum testosterone is possibly of pituitary origin achieved by the feedback phenomenon.

\section{Female reproductive function}

Effect of cadmium on the sexual cycle (Vaginal): According to the vaginal smears, it is noted that the treated rats (C1 and $\mathrm{C} 2)$ show the same cyclic variations as those of the controls. The oestrus stage, which is characterized by the abundance of keratinized cells in the vagina, as an indicator of normal female fertility, is present in all the three groups ( $\mathrm{T}, \mathrm{C} 1, \mathrm{C} 2$ ) with almost the same percentage. This leads us to think of a course of a normal sexual cycle despite the administration of cadmium.

Effect of cadmium on the pregnancy rate and the number of implantations: Mating between males and females of the different groups after 90 days of treatment showed a decrease of the pregnancy rate for the two doses $\mathrm{C} 1$ and $\mathrm{C} 2$ administered in males or females. the average number of implantations per litter also shows a decrease. Thus, it can be said that the effect of cadmium is manifested directly on the uterus since the treated females $\mathrm{C} 1$ and $\mathrm{C} 2$ show relatively low pregnancy and implantation rates despite the presence of a normal vaginal cycle identical to that of the female controls.

\section{Discussion}

Many studies showed that $\mathrm{Cd}$ goes through calcium channels to enter the cells [1]. Indeed, $\mathrm{Cd}$ is not essential for the development of animal or plant organisms and does not participate in the cell metabolism. However, its physical and chemical properties, which are close to those of calcium, enable it to cross the biological barriers and accumulate in the tissues. It is considered to be an extremely toxic pollutant [2], and its toxicity is particularly at the bone and renal level=besides, its concentration in the living organisms along the food chains makes this metal well known to toxicologists. During gestation and the perinatal period, then during the first years of life, the almost permanent exposure to chemical pollution constitutes a serious attack on the fate of the baby and the small child. Since the beginning of its existence, while it is still an embryo, the future child is continuously exposed, to physical and chemical toxic agents via the transplacental passage even before its conception or during its gestation as it absorbs residues of toxic substances.

Numerous studies suggested the harmful effect on reproductive function of certain factors present in our environment, among which, we can mention cadmium, which is a metal of a high toxicity $[3,4]$. Indeed, several studies showed a positive correlation between testicular atrophy and exposure to different toxic agents such as cadmium, nickel and DDT.

A histological study performed on cadmium-treated rat testes shows an attack on most of the atrophying seminiferous tubes $\overline{\text { a blockage }}$ of spermiogenesis and / or the presence of trabeculae at the walls of these tubes, which is probably an indicative of destruction of the sertoli cells. The spermatogenesis that takes place within the seminiferous tubes is a complex process with particular cell differentiations the regulation of which is imperfectly known. This process shows 3 phases of differentiation at the level of the seminiferous epithelium, namely, 
Citation: Boujelben M, Abdennabi R, Guermazi F, Elfeki A (2018) Impact of Cadmium on the Endocrine and Exocrine Sexual Activity in the Adult Male and Female Wistar Rats: Determination of an Apoptotic Process. J Environ Anal Toxicol 8: 552. doi: 10.4172/2161-0525.1000552

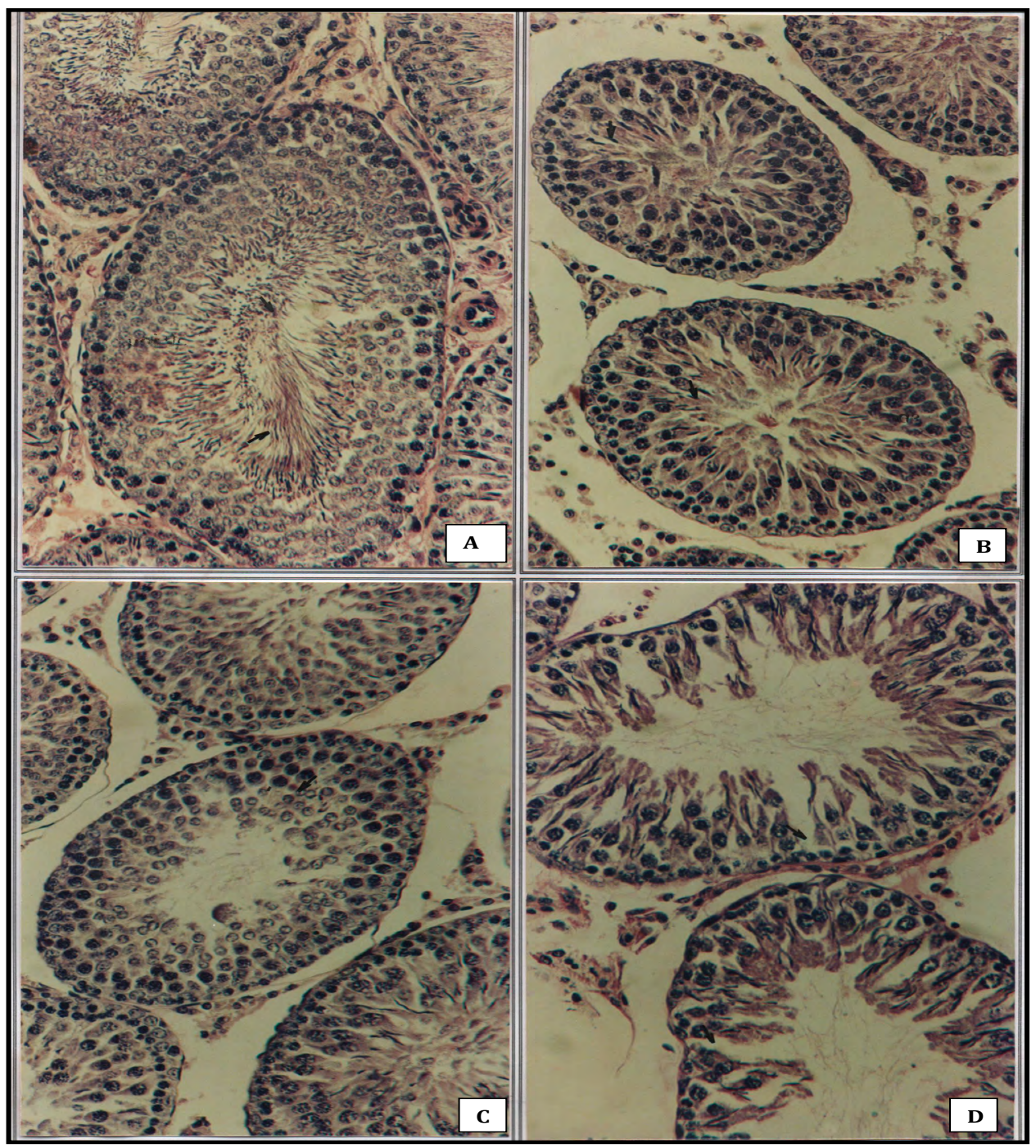

Figure 3: Histological structures of testicles from control (A) rats treated with cadmium chloride (B) administered in drinking water at a concentration of 10 mg/l for 60 days (C1), showing different types of alterations: blocking of spermiogenesis: (B) spermatozoa without flagella. (C) total absence of spermatozoa. Destruction of sertoli cells: (D) presence of spans in the seminiferous tubules Staining: hematoxylin-eosin (Grx200).

an increase of the number and size of the stem cells (spermatogonia and spermatocytes) by several mitoses, a reduction of the number of chromosomes by meiosis (spermatocytes II and spermatids) and spermatozoa production from spermatids by spermiogenesis. These steps involve regulatory factors of pituitary (LH and FSH) or testicular (Leydig and Sertoli cells) origin. Spermatogenesis can be affected by several exogenous physical or chemical factors. Indeed, the germ line is very sensitive to the $\mathrm{X}$-ray radiation, which destroys them and to the environmental conditions [5] whether chemical (pesticides, heavy metals) [6] or behavioral (smoking, alcoholism). Thus, cadmium salts can cause testicular alterations, such as irreversible lesions and decreased reproductive capacity.

Numerous human studies indicate a decline in the number and quality of male sex cells in recent years. It therefore seems that the disruption of the reproductive system is multiplying, even leading to alterations in various animal species. This is because of the high sensitivity of the reproductive processes to disturbances by exogenous agents, such as pesticides, drugs, organic solvents, heavy metals. which are considered as true toxic agents affecting both the male and female reproductive function. These toxic compounds may interfere with neurophysiological processes involved in reproduction or indirectly with gametogenesis. For males, the process of spermatogenesis can be altered, either directly by inhibition of germinal cell maturation (at different stages), or indirectly by disruption of essential endocrine functions regulating their synthesis and secretion. For females, oogenesis can be disturbed both directly by oocyte destruction and indirectly by inhibition of the ovarian cycle and / or uterine cycle. The concentration of cadmium, zinc and lead in the tissues of various reproductive organs is found to increase with age in all the examined reproductive organs, the highest content of which is found in the seminal vesicles and the epididymis.

A study conducted on workers exposed to cadmium showed that this metal contributes to a decrease of the motility of their spermatozoa, an increase of the morphological deformations of their sexual cells 
Citation: Boujelben M, Abdennabi R, Guermazi F, Elfeki A (2018) Impact of Cadmium on the Endocrine and Exocrine Sexual Activity in the Adult Male and Female Wistar Rats: Determination of an Apoptotic Process. J Environ Anal Toxicol 8: 552. doi: 10.4172/2161-0525.1000552

Page 5 of 7
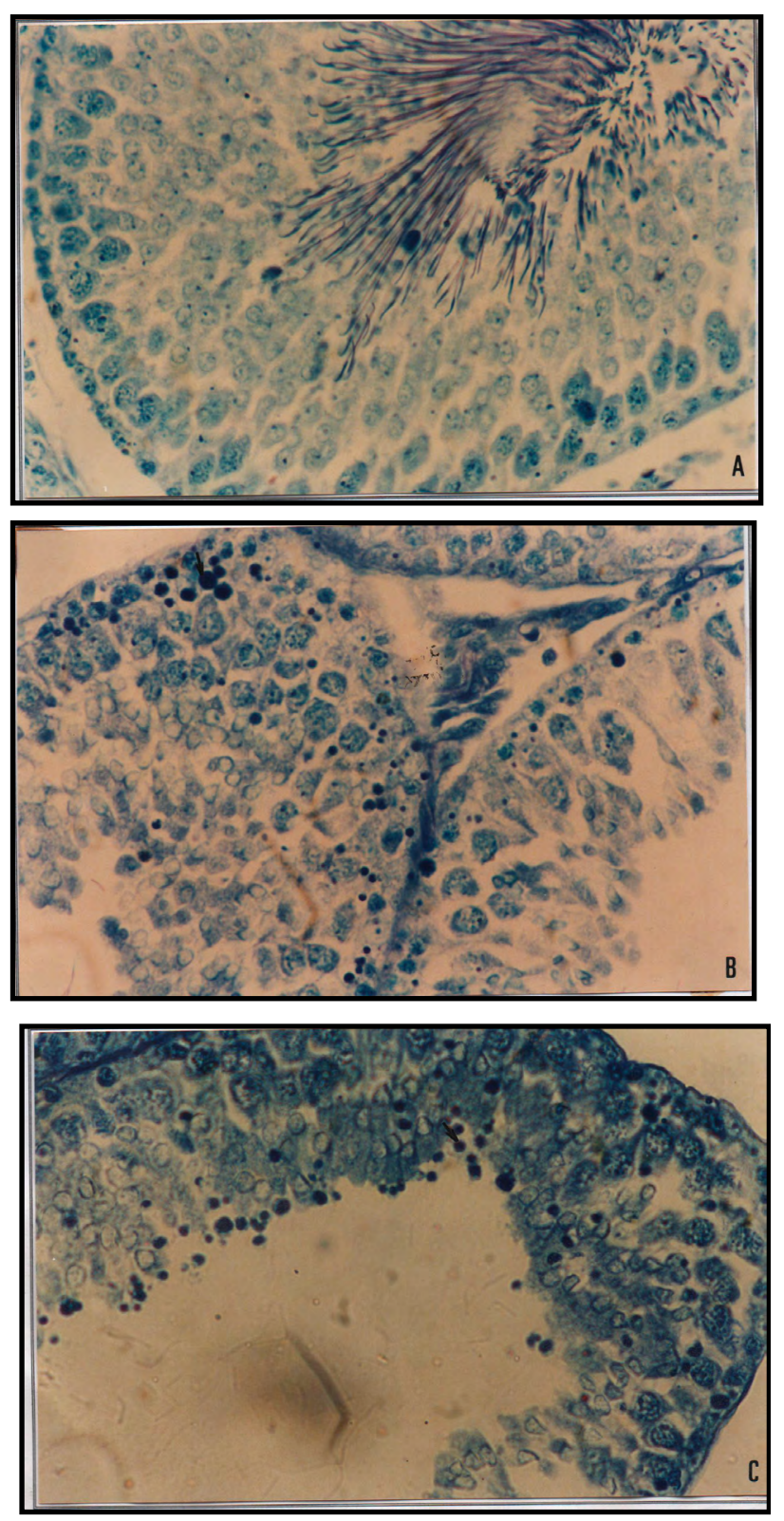

Figure 4: Histological structures of testicles of control (A) rats treated with cadmium chloride (B and $\mathbf{C}$ ) administered in drinking water at a concentration of $10 \mathrm{mg} / \mathrm{l}$ for 60 days. Coloring: toluidine borate blue (Grx400).

and their density. Therefore exposure to cadmium with a blood concentration less than $10 \mu \mathrm{g} / \mathrm{l}$ can lead to a significant decrease of the reproductive capacity of men [7]. There is a significant correlation between cadmium blood levels and changes in sex parameters (sperm volume, sperm viability and motility and morphology). In fact, a high cadmium concentration can affect spermatogenesis and consequently the male fertility [8]. Another study indicated that the administration of $\mathrm{CdCl}_{2}$ and $\mathrm{HgCl}_{2}$ (0.005-0.5 mmol / l) causes a significant reduction of the quality and quantity of sperm entering the cervical mucosa.

A hormonal dose of serum testosterone during our experimental study shows a fall in its level on the 1st and 5th day for patients treated with the 1st $\mathrm{C} 1$ dose. Indeed, several studies showed that some toxic substances, such as cadmium, are inhibitors of enzymatic reactions resulting in gonadic steroidogenesis from cholesterol. Moreover, an adjustment beyond these dates is noticed since the rate of testosterone returns to normal despite the continuation of treatment, and sometimes it exceeds that of the controls. In this case, there a compensatory hypersecretion. In fact, endogenous regulatory systems intervene to correct some disturbances. For example, the feedback mechanism stimulates the pituitary gland to secrete more LH and FSH which, in turn, stimulate the testicle to correct this deficiency. Protective stress proteins, anti-stress hormones. could be at the origin of the increase of the body's performance to fight against cadmium poisoning and correct some sexual damage. However, the persistence of the decrease of the number and motility of spermatozoa, testifies to the local cytotoxic effect of cadmium on spermatogenesis, so these local effects escape any corrective regulation. Indeed, [4] assumed that the decrease of fertility is due to the sperm chromatin alteration and not to a decrease of the serum testosterone levels. It is thus a cytotoxic effect inducing consequently the phenomenon of apoptosis. Indeed, many pollutants, such as: DDT, dieldrin, nitric oxide (NO), styrene. are considered as being oxidative stresses and their cytotoxic and genotoxic effects seem to be exerted by the process of apoptosis [9-12]. Regarding the impact of $\mathrm{Cd}$ on female rats, it seems that female fertility is affected, as the pregnancy rate as well as the number of implantations decrease in treated females $\mathrm{C} 1$ and $\mathrm{C} 2$.

According to Rieutort et al. in rats as in all the rodents, changes in the genital tract predominate in the vagina. The vaginal smears thus make it possible to follow the course of this cycle comprising 4 stages and lasting from 4 to 5 days in this animal species. According to the results found in our experimental study, the vaginal smears performed in the controls and the treated rats $\mathrm{C} 1$ and $\mathrm{C} 2$ show a normal oestrus cycle for the different groups. Several studies showed that some toxic substances can affect the oestrus cycle but at well-defined doses. On the other hand, Tafelski and Lamperti showed that lead acetate at concentrations higher than $500 \mu \mathrm{g} /$ day can affect the oestrus cycle. The fact that pregnancy and implantation rates drop despite a normal vaginal cycle shows that it is probably a direct action of $\mathrm{Cd}$ on the uterus, which causes a nesting problem. Indeed, heavy metals, such as lead, induce a delay in fish in ovarian development and a decrease of the number of nest eggs (implanted). Similarly, Nordstrom et al. showed a significant increase of spontaneous abortions of pregnant females living in the vicinity of smelters.

Other studies showed that exposure to an area polluted with cadmium causes a decrease of fetal fertility and growth and specifically malformations [13]. Exposure to $50 \mathrm{ppm} \mathrm{Cd}$ during lactation or pregnancy decreases the body weight and fetal viability [14], besides, it can be a direct action on the oocyte. Indeed, it has been found that another metal, such as lead, could be responsible for ovulatory dysfunction [15]. Heavy metals in general can influence female fertility at each breeding season [16]

\section{Conclusion}

In summary, our study shows that chronic exposure to cadmium causes a double sexual disorder in male and female rats: first, disorder in the hormonal function, which is affected at the early stages of poisoning, but is rabidly corrected; second, disorder in the genital tract, which affects the testis and the ovary, resulting in a reduction of fertility in both $\mathrm{C} 1$ and C2. In males, cadmium induces, pathological changes in spermatogenesis observed by histological study [17-22]. In fact, an alteration in the structure of the seminiferous tubules with 
Citation: Boujelben M, Abdennabi R, Guermazi F, Elfeki A (2018) Impact of Cadmium on the Endocrine and Exocrine Sexual Activity in the Adult Male and Female Wistar Rats: Determination of an Apoptotic Process. J Environ Anal Toxicol 8: 552. doi: 10.4172/2161-0525.1000552

Page 6 of 7

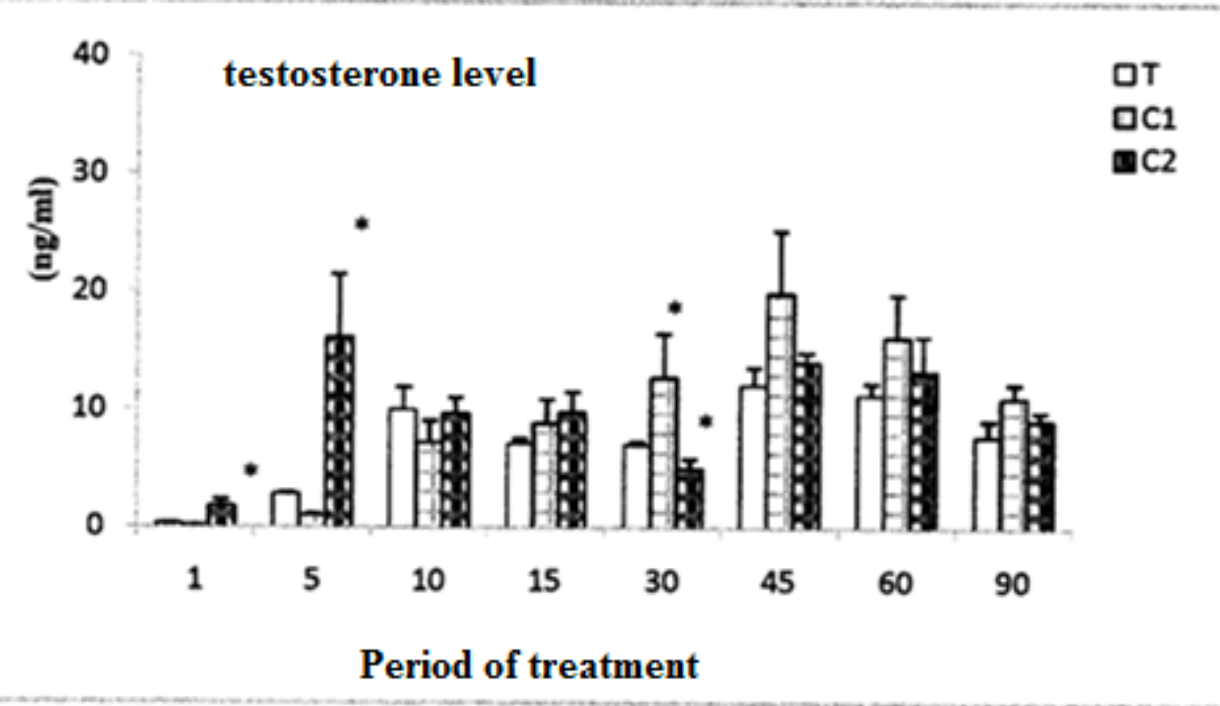

Figure 5: Evolution of serum testosterone level in $(\mathrm{ng} / \mathrm{ml})$ in male rats controls $(\mathrm{T})$ and treated with cadmium chloride $(\mathrm{C} 1$ and $\mathrm{C} 2)$ during $5,10,15,30,45,60$ and 90 days. The values represent the mean \pm Standard Deviation $(n=8)$. *: $P \leq 0.05$ compared with the control rats.

blockage of spermatogenesis is also noted. Moreover, the presence of male gametes without flagella or total absence of spermatozoa with a destruction of the sertoli cells are testified by the presence of spans) and a decrease of motility and the number spermatozoa at the end of the treatment. The cytotoxic effect of cadmium on males seems to be related to an apoptotic process. In females, the vaginal cycle shows almost no variation during the cadmium treatment where oestrus is still present (normal vaginal activity). However, the inter-group pairing experiments show that fertility is low when it is a female or a treated male $(\mathrm{C} 1$ or $\mathrm{C} 2)$. It therefore seems that the cytotoxic effect of $\mathrm{Cd}$ in this case is localized in the uterus.

\section{Conflict of Interest}

The authors declare no conflict of interest. The founding sponsors have not been involved at any stage of the study. They participated neither in the design and the conduction of the experiment, nor, in the analysis of the data or the preparation of the manuscript for publication.

\section{Acknowledgements}

The Authors would like to thank the Faculty of Sciences of Sfax, Tunisia, University of Sfax.

\section{References}

1. Simkiss T (1995) Transport of metals across the membrane of aquatic organisms. Metal speciation and bioavailability in Aquatic Systems, pp: 1-44.

2. Johannes G, Franziska S, Christian GS, Vera E, Paul B, et al. (2006) The toxicity of cadmium and resulting hazards for human health. $\mathrm{J}$ Occup Med Toxicol 1: 22.

3. Omu AE, Dashti H, Mohamed AT, Mattappallil AB (1995) Significance of trace elements in seminal plasma of infertile men. Nutrition 11: 502-505.

4. Benoff S, Hurley IR, Barcia M, Mandel FS, Cooper GW, et al. (1997) A potential role for cadmium in the etiology of varicocele associated infertility. Fertility and Sterility 67: 336-347.

5. Bujan L (1998) Le plomb dans l'atmosphère. Recherche 198: 446-445.

6. Foster J, Liston G, Koster R, Essery R, Behr H, et al. (1996) Snow cover and snow mass intercomparisons of general circulation models and remotely sensed datasets. Journal of Climate 9: 409-426.

7. Telisman S, Cvitković P, Jurasović J, Pizent A, Gavella M, et al. (2000) Semen quality and reproductive endocrine function in relation to biomarkers of lead, cadmium, zinc, and copper in men. Environmental Health Perspectives 108 45.

8. Chia SE, Ong CN, Lee ST, Tsakok FH (1992) Blood concentrations of lead cadmium, mercury, zinc, and copper and human semen parameters. Archives of Andrology 29: 177-183.

9. Cai W, Chen K, He L, Cao Q, Koong A, et al. (2007) Quantitative PET of EGFR expression in xenograft-bearing mice using 64 Cu-labeled cetuximab, a chimeric anti-EGFR monoclonal antibody. European Journal of Nuclear Medicine and Molecular Imaging 34: 850-858.

10. Inaba K, Turley S, Yamaide F, lyoda T, Mahnke K, et al. (1998) Efficient presentation of phagocytosed cellular fragments on the major histocompatibility complex class II products of dendritic cells. J Exp Med 188: 2163-2173.

11. El-Gohary M, Awara WM, Nassar S, Hawas S (1999) Deltamethrin-induced testicular apoptosis in rats: the protective effect of nitric oxide synthase inhibitor. Toxicology 132: 1-8.

12. Tebourbi L, Courtot AM, Duchateau R, Loeuillet A, Testart J, et al. (2001) Experimental inoculation of male mice with murine cytomegalovirus and effect on offspring. Human Reproduction 16: 2041-2049.

13. Kreis TE, Lowe M, Pepperkok R (1995) COPs regulating membrane traffic Annual Review of Cell and Developmental Biology 11: 677-706.

14. Piasek M, Schönwald N, Blanuša M, Kostial K, Laskey JW (1996) Biomarkers of heavy metal reproductive effects and interaction with essential elements in experimental studies on female rats. Arhiv za higijenu rada i toksikologiju 47: 245-258.

15. Tafelski TJ, Lamperti AA (1975) Failure of lead acetate to alter the reproductive cycle of female rats. IRCS Journal of Medical Science 3: 449.

16. Gerhard I, Runnebaum B (1992) Environmental pollutants and fertility disorders Heavy metals and minerals. Geburtshilfe und Frauenheilkunde 52: 383-396.

17. Bearer CF, Lee S, Salvator AE, Minnes S, Swick A, et al. (1999) Ethyl linoleate in meconium: a biomarker for prenatal ethanol exposure. Alcoholism: Clinical and Experimental Research 23: 487-493.

18. Calabrese EJ, Stanek E, James RC, Roberts SM (1997) Soil ingestion: a concern for acute toxicity in children. Environmental Health Perspectives 105 : 1354.

19. Panova IG, Tatikolov AS (2011) Izvestiya Akademii Nauk, Seriya Biologicheskaya 2: 235-239.

20. Madkour M, Brucellosis M (1996) Textbook of Medicine. 3rd edn. Oxford University Press, pp: 619-623. 
Citation: Boujelben M, Abdennabi R, Guermazi F, Elfeki A (2018) Impact of Cadmium on the Endocrine and Exocrine Sexual Activity in the Adult Male and Female Wistar Rats: Determination of an Apoptotic Process. J Environ Anal Toxicol 8: 552. doi: 10.4172/2161-0525.1000552

Page 7 of 7

21. Nordenson I, Beckman G, Beckman L, Nordstrom S (1979) Occupational and environmental risks in and around a smelter in northern Sweden. Heredifas 90: $291-296$
22. Wu C (1995) Heat shock transcription factors: structure and regulation. Annual Review of Cell and Developmental Biology 11: 441-469. 